Página inicial: 393 - Página final: 400

TIPO DE ARTÍCULO: DE REFLEXIÓN

\title{
SOBRE LA MEMORIA, LA CONCIENCIA Y EL PENSAMIENTO EN AMÉRICA LATINA. ENTRE LA LAGUNA Y EL PANTANO.
}

ON THE MEMORY, CONSCIOUSNESS, AND THOUGHT IN LATIN AMERICA. BETWEEN THE LAGOON AND THE SWAMP.

RECIBIDO: ENERO 2015 REVISADO: ABRIL 2015 CEPTADO: 2 DE MAYO DE 2015

Por: Pablo Tasso. ${ }^{1}$

\section{RESUMEN:}

En el presente texto se desarrollan algunas rutas de análisis en torno a la pregunta ¿cómo incorporar éticamente el problema en sus acciones cotidianas, y del mismo modo, cómo evitar las exitosas estrategias del olvido y la indiferencia?; Se hace énfasis en la ganada importancia que tienen los procesos populares sobre todo juveniles, en tanto que, gracias a sus narrativas, acrecientan y triunfan cotidianamente sobre las retóricas autoritarias que buscan silenciar la memoria.

\section{PALABRAS CLAVE:}

Memoria, olvido, conciencia, jóvenes.

\section{ABSTRACT:}

Some routes of analyses around the following question: How to incorporate ethically the problem in their daily actions, and similarly, how to avoid the successful strategies of oblivion and indifference? are addressed in this paper. Certain emphasis is made on the gained importance that the popular processes have specially those related to the youth, while, thanks to their narratives, they increase and succeed, on a daily basis, over the authoritarian rhetoric seeking to silence memory.

\section{KEY WORDS:}

Memory, oblivion, consciousness, and youth.

1 Doctor en Historiografía. Director del Centro de Documentación e Investigación Hugo Zemelman (Ipecal-UM). México. Contacto: pablotasso@gmail.com pablotaso@ipecal.edu.mx 


\section{Introducción.}

Las sociedades latinoamericanas se ven desafiadas por el antiguo problema de la memoria de sus víctimas y su exclusión de los relatos del presente. En este sentido, las memorias de la violencia contemporánea se presentan como un síntoma de las políticas del olvido, y a la vez, un síntoma de nuevas ciudadanías que reclaman su lugar en la historia moderna. No está claro si estas ciudadanías lograrán transformar las culturas políticas latinoamericanas -puesto que esto hace a lo central de las dinámicas políticas del momento actual-, pero algunas sociedades parecen estar haciendo un giro cultural a partir de atribuirse la responsabilidad de construir sus propias memorias del pasado, por fuera de los relatos oficiales dominantes.

Antes de plantearse el problema de cómo se vinculan memoria con conciencia y pensamiento conviene advertir que cómo ya plantearon muchos autores para la experiencia europea, también en América Latina hay una tensión clara entre los esfuerzos de la memoria y las políticas de olvido que atraviesan todos los sectores de la vida social. Por un lado, muchas ciudadanías latinoamericanas parecen expresarse contra la naturaleza y las dimensiones de la memoria artificial -como le llamó (Ricoeur, La memoria, la historia, el olvido, 2003) que les avasalla con relatos que les son inaceptables. Esta memoria artificial, a través de las que los poderes estatales lograron construir culturalmente cada país, es ahora lograda a través de una narrativa que impone y bloquea representaciones del pasado y por lo tanto, impide que las sociedades construyan y reflexionen no sólo sobre sus memorias sino especialmente impidiendo que lo hagan sobre sus proyectos, que es en dónde cobran sentido las ideas de conciencia y de pensamiento.

La tarea de obstaculizar la reflexión sobre los sucesos políticos, económicos y culturales supone también fragmentar, impedir o manipular los esfuerzos memoriales de las sociedades, dice Ricoeur. Es posible que esto marque nuestras épocas, ya que las expectativas de un razonamiento colectivo a través del consenso público son parte de una representación de los poderes dominantes que no se condice con el funcionamiento del mercado de ideas de las sociedades latinoamericanas. En realidad, lo que llamamos consenso social hace mucho que fue conceptualizado como resultado de un proceso de consentimiento de las acciones de los poderes constituidos (Ramonet, 1986) (Chomsky \& Herman, 1988)(Castells, 2009) Esto quiere decir, que no hay que suponer que las sociedades, sobre todo las nacionales, tienen muchas capacidades colectivas de razonamiento o incluso, capacidades de tomar decisiones, porque estas se encuentran muy condicionadas por el accionar de los poderes con capacidad de representación. Esto, que supone un desafio en un plano político, también lo supone en otros planos, como el trabajo de los historiadores, sin los cuales no pueden operar la mayoría de las disciplinas sociales.

\section{La memoria como matriz de la representación histórica.}

La riqueza del ejercicio y del debate en torno a la memoria en la región (que abarca debates acerca de la naturaleza del fenómeno, conceptualizaciones, funcionamiento y posibilidades) son un sintoma de fuerza con que ciertas sociedades buscan incidir en los significados y organización de los relatos del pasado. Las razones por las que incidir en la construcción del pasado pueden parecer obvias: "discutir el pasado es central porque sus representaciones configuran y validan, no sólo los episodios y experiencias del pasado, sino también las opciones de futuro de una sociedad" (Pappe, 2007). Este es el escenario en que se dan algunos debates, como los que hacen a las tareas de la historia y la memoria como dispositivos para pensar el pasado, que es el territorio colectivo de la intelección, y uno de los sillones en la antesala del pensamiento social. 
Antes de interpretar las tensiones entre ambos conceptos como oposiciones, como ha planteado Pierre Nora, conviene apreciar que siendo simbióticas, memoria e historia tienen problemáticas en sí mismas además de las problemáticas que supone su propia relación. Y siempre considerando que c'est la mémoire qui dicte et l’histoire qui écrit, como ha sostenido. También Ricoeur coincide en el carácter matricial de la memoria para la tarea de los historiadores, lo que no siempre se cumple por los intereses que se oponen a quienes hacen memoria (Ankersmit, 2001) Esto supone muchos desafios para quienes trabajamos con representaciones del pasado desde muchos campos de conocimiento, sobre todo porque las memorias impedidas tanto como las abusivas se manifiestan en la dificultad y éxito desigual para construir lógicas de razonamiento propias, lo que es parte fundamental de las nacionalidades latinoamericanas y también del pensamiento personal.

Pese a algunos de estos debates, el nuestro es también por qué la memoria no ha funcionado como matriz de la historia de sus sociedades. Este podria situarse como problema del presente en el sentido de que lo que está en juego es el triunfo de las políticas del olvido. En el caso de las sociedades latinoamericanas, echar al olvido las voces de las víctimas de los estados modernos no solo parece la validación de las políticas de control represivo, sino también la invalidación de las opciones de futuro contenidas imaginariamente en las sociedades reprimidas: sus valores, sus recuerdos, sus ideas y todo aquello que, amén de ser o no amenazante, formaba parte de lo posible que se arrincona al silencio y a lo impensable. Olvidar el pasado, escribió Zemelman, orilla a América Latina a "destruirse e inventarse constantemente", erosionando las posibilidades de tener proyecto a partir del pensamiento colectivo (2000, p 131)

\section{La memoria oficial como memoria artificial.}

Una de las posibilidades de trabajar sobre el término memoria es el de pensarla dentro de la trama cognitiva de una sociedad determinada, y como parte fundamental de la conciencia colectiva. El problema se ha abordado muchas veces, aunque no es nuestro objetivo reseñar dónde ni cómo. Caben sin embargo incorporar algunos asuntos acerca de los efectos de la manipulación de la memoria para las sinápsis sociales que suponen el verdadero ejercicio democrático.

El primer problema tiene que ver con las dificultades de pensar con y más allá de nuestro colectivo, aspectos para los que la memoria funciona como condición para reproducir ciertos pensamientos, a recortar o a completar nuestros recuerdos como si se tratara de recuerdos propios y fidedignos. El individuo piensa al interior de los marcos que sociedad y grupos le construyen a los individuos (Halbawchs, 1992) y la reducción de esos marcos, o la construcción de otros nuevos, es la verdadera operación política de los autoritarismos latinoamericanos. Por ello, los sujetos están desafiados a moverse de ellos con la conciencia de que se trata de marcos condicionantes de las subjetividades personales y colectivas. Por otro lado, con un espíritu más sociológico que antropológico, y como aporte a los problemas del lenguaje, Mills pensaba que estos marcos se traducian operativamente para regular las predisposiciones del individuo en "vocabularios de motivo", para condicionar "los términos con los cuales se produce una interpretación de la conducta por los actores sociales" (Wrigth Mills, 1964). Y basta regular la interpretación de una conducta, como afirman los estudiosos de las culturas politicas, para que las prácticas se manifiesten al interior de esos encuadres.

Sin lugar a dudas, las historias coloniales y en especial la americana, fueron un escenario especial para el desarrollo de estos mecanismos de organización y control de la discursividad social. El siglo de dominación norteamericana -su especial atención a la cultura- y modernización de los estados autoritarios en la región replantearon el problema del pasado que hoy emerge en el territorio de la memoria, que no sólo es parte fundamental 
de la construcción hegemonía sino también de la constitución de la conciencia histórica de los pueblos. La memoria social es entonces el territorio donde la conciencia colectiva siente la intervención de los poderes. En este sentido, la lucha de las víctimas consiste en evitar que ciertos episodios sean replegados de la memoria, hacia la laguna y por lo tanto, hacia el olvido. En nuestro contexto, la lucha contra este repliegue busca evitar, quizá no tan concientemente, que ciertas interpretaciones no sean arrinconadas al territorio de lo indecible e impensable (Angenot, 2010) Como proyecto, la cultura del capitalismo, es una máquina eficiente de segregación, o podría también decirse, de inutilización de las memorias de las víctimas. Y también, una máquina capaz de obtener un alto grado de perfeccionamiento en la construcción insoslayable de sus nuevas víctimas, es decir, en la creación de unas víctimas que ya no saben que lo son, o que el dolor ya no existe en ellas.

El caso mexicano, que hemos estudiado con mayor profundidad, revela los tempranos debates acerca de las interpretaciones colectivas y las posibilidades de las memorias de ser intervenidas mediante la renovación del aparato narrativo de gobierno. Se trata de un caso dónde la elite llegó a advertir -hace medio siglo- que la necesidad de controlar las ideas no sólo afectaba a las maniobras circunstanciales de un gobierno, sino de evitar que "las opiniones de una generación" se transformaran "en la politica de la generación siguiente" (Tasso, 2014) La puesta en juego de ese gobierno en aquella situación de descontento, como la que supuso el movimiento estudiantil de 1968 y su masacre en Tlatelolco, evidenció las posibilidades de los poderes en la constitución de una trama de significados y motivaciones para los actores sociales que perduraria durante las décadas posteriores. Esta trama logró anclar a miles de actores políticos en el sitio que la retórica oficial necesitaba para explicar su colisión con ellos y, por supuesto, marcar el rumbo de lo tolerado con la eficacia que el cauce tiene con el agua que lo atraviesa. Y más allá de sus políticas de olvido -hay que recordar que el lema pos-tlatelolco del movimiento estudiantil sería "2 de octubre: no se olvida"-, lo que el poder mexicano logró con su justificación de la matanza, fue trascender a ella. Y con ese aprendizaje decisivo, las elites autoritarias latinoamericanas en general, obtuvieron una referencia modélica para solucionar los descontentos.

Muchos son los factores que intervinieron en este momento autoritario, indudablemen la guerra fría colaboró en la construcción de un escenario simbólico para esta forma de dirimir en la política. La ola de guerras libertarias, por otro lado, explicó la creencia de algunos grupos en que la opresión derivaba en rebelión. En el caso de 1968, sin embargo, lo que se suponía un debate al interior de las fuerzas de lucha democrática, pudo ser trasladado a la ilegalidad por la vía de la represión. La complejidad de este tránsito, insistimos, asoma en la región como un síntoma traumático: imposición, negación, amnesia, olvidos... memoria artificial. Cómo en muchos de los procesos de constitución de los estados-nación, las politicas de olvido sobre las soluciones sanguinarias son aceptadas y resistidas (Palti, 2003) El problema son las actuales capacidades de los poderes modernos para imponer memorias que negativizan y velan aspectos de la sociedad, memorias que luego ocupan el lugar de la experiencia y de las que es muy dificil puede escapar en la vida cotidiana.

\section{Quehacer y qué hacer con la memoria.}

Como dijo Nora, mientras los trabajos del historiador pertenecen a la vida prosaica, la memoria pertenece al territorio de lo sagrado. Censurables y trastocables, los recuerdos guardan un tesoro, que aun cuando pueda ser temporalmente inaccesible, contiene lo necesario para reflexionar sobre la experiencia humana. A la vez, la memoria funciona como dique o limite de lo incoherente e inaceptable. Sin embargo, la memoria es un hecho de la experiencia y pueden hacer memoria de esa experiencia sólo sus protagonistas. Para ellos, la memoria configura una realidad que no se puede abandonar, sino con la muerte o 
la locura. El problema lo plantearon tempranamente los tlamatimine aztecas en la ciudad de México, como primera respuesta articulada a la nueva forma de interpretar el mundo que ofrecian los curas y los administradores españoles.

La respuesta de 1524 no refuta las creencias de sus conquistadores, se las declara inaceptables porque no honran la memoria. Los sabios aztecas creían que lo que los curas y españoles les proponían un relato que supone para ellos una ruptura con sus "progenitores", con "los que han vivido sobre la tierra" y quienes les "dieron su norma de vida". Y con una claridad asombrosa ante lo que parece la pérdida del sentido de la existencia, se preguntan: "Y ahora, nosotros, ¿destruiremos la antigua norma de vida?". Y reflexionan que ya "es bastante que hayamos perdido nuestro poder..." como para admitirse sustituir sus interpretaciones históricas. Y le advierten a los españoles que seguirán pensando lo que piensan "aun cuando los ofendamos", porque "nosotros sabemos a quién se debe la vida, a quien se debe el nacer..." Y además, haciendo uno de los primeres silogismos históricos que conocemos de la modernidad indígena americana advierten, que si no son respetados en su derecho a pensar de acuerdo a su memoria perecerán: "si permanecemos [sin memoria] sólo seremos prisioneros. Haced de nosotros los que queráis. Esto es todo lo que respondemos" (Dussel, 1994).

Como se desprende, los quehaceres de la memoria suponen desafíos dramáticos. Hacer memoria supone, como se ha dicho, poder. Porque hacer memoria no es sólo "recibir una imagen del pasado; es también buscarla, haceralgo" con ella (Ricoeur, La memoria, la historia, el olvido, 2003), y hacer algo con ella supone poder hacer memoria primero. Los riesgos de esta operativa son y fueron grandes: la deformación, la amnesia, las manipulaciones, las proyecciones, tal y como le preocupó a Freud. De ahí que la memoria no sea un hecho de la naturaleza al que podemos asistir como testigos, sino algo que asumir como lucha por evitar prohibiciones y negaciones. Acoger esta memoria para quienes no fueron directamente víctimas -conviniendo en la complejidad del término, y en las batallas de significado que acoge-, supone aún más problemas. En primer término porque la memoria refiere a lo vivido, y en este sentido, el relato de las víctimas a muchos les resulta ajeno especialmente como memoria. Cabe entonces el desafio como apropiación ética, de descubrimiento de aquello que, sin ser experiencia personal, afecta los horizontes de vida como invalidación de opciones de futuro. Esa puede ser una de las funciones de hacer historia con la memoria.

La creciente conciencia acerca de la capacidad de los aparatos culturales para obligar a sociedades enteras a subsistir sin memoria propia es alentador. Este malestar podría estar marcando una tendencia sobre en unos de los abusos más problemáticos para las sociedades que aspiran a la democracia. Como contraparte al malestar y la incoherencia de los nuevos hábitos y memorias conviene recordar que también hay grandes sectores que se adaptan avienen con entusiasmo a las nuevas propuestas de olvido y desmemoria: "los naturales" -escribía Fray Toribio Motolinía en la misma década en que los sabios aztecas se negaban a contradecir a su memoria-: "están tan dispuestos e aparejados como cera blanda para imprimir en ellos toda la virtud” (Bernard \& Gruzinski, 1996). De este modo, no es fácil asegurar que las sociedades latinoamericanas vivan un giro memorial y se hayan curado de los proyectos de historia oficial.

En la trama de experiencias latinoamericanas lo mismo se ven tantos colectivos amnésicos como de aquellos que no encuentran el sentido para hacer memoria. De este modo, el olvido funciona como el fracaso de las sociedades en su capacidad de producir futuro más allá de los poderes con capacidad de producir memorias y motivaciones. Por ello, la idea misma de memoria, no sólo refiere a un problema de la cognición del pasado, sino que también refiere a un dilema de la historicidad de los colectivos sociales. Latinoamérica, espacio de 
la última oleada de institucionalidades modernas, es el territorio en el que el debate acerca de la memoria deberá transformarse en justicia, pero también en el gran problema de la colonización del imaginario, de la colonización del pensamiento. Especialmente porque conocimiento, razonamiento y pensamiento se encuentran determinadas en sus opciones y posibilidades por la existencia de una memoria utilizable.

\section{Conclusiones.}

En estos días, México vive conmovido a la muerte y desaparición de 43 jóvenes estudiantes del magisterio rural. Este, como otros momentos de conmoción, parece despertar las conciencias. Pero corren los dias y las organizaciones sienten que el esfuerzo siempre ha sido insuficiente. En ese contexto, una carta de los hijos de los desaparecidos de las décadas del setenta, expresa las dificultades de encontrar un sitio de lucha, incluso para ellos que hicieron de la memoria una categoría colectiva:

[Tras estos acontecimientos] H.I.J.O.S. México anuncia que se replanteará su actuar (...) Esa alegría que algunos admiraban se nos borró de golpe en Ayotzinapa; los colores que solemos usar se están quebrando entre nuestras muelas apretadas de dolor y rabia. Y no nos vengan a contar aquella historia de la alegría y la esperanza... (Hijos de México, 2014)

Las preguntas pueden resultar obvias cuando regresan al problema de cómo es una sociedad en la que sus memorias son impedidas y manipuladas.

¿Qué efectos tiene en sus capacidades de pensar el presente? ¿Qué tipo de sujeto es aquél que no puede acceder a su memoria, que en lo cultural es también parte de una memoria colectiva que enmarca la suya? ¿Cómo es pensar el presente y sobre todo, construir el futuro desde una memoria perdida? ¿Qué efectos tiene en su localización histórica el no poder acceder a las naturalezas de los actores sociales y politicos de la historia reciente? ¿Qué significa construir conocimiento en el marco de una memoria controlada? ¿Cuál es el papel de los maestros frente a jóvenes con representaciones del pasado artificializadas? ¿Cuál es el papel del intelectual latinoamericano consciente de estas fracturas de la memoria en la región? (Richard, 2007).

No hay respuestas simples. Zemelman abogaba por abjurar de la tarea "fácil" de "transferir responsabilidades". Y señalaba algunos rumbos: que ampliáramos la conciencia "de qué fue lo que pasó con el pensamiento" en América Latina. Que había que "asumir el problema en términos de oficios, de las profesiones de cada cual, ya sea que construyan conocimiento, ya sea que enseñen, o, en este caso, que trabajen la conexión entre enseñar y construir conocimiento" $(2000,140)$.La propuesta de IPECAL de trabajar a partir de la biografia personal hasta convertirla en un objeto didáctico que estructure las tareas del conocer y del pensar son también un síntoma de una época en la que se están enfrentando estos problemas desde los sujetos. Así, el desafio de las sociedades latinoamericanas frente a la memoria de las víctimas puede estar abriendo muchos resquicios de luz. Las ciencias sociales también están viendo nacer nuevas formas de ejercer ciudadanía sin que sea fácil entrar en relación con ellas.

La importancia de trabajar sostenidamente sobre los dilemas de esta dinámica de olvido y memoria, tienen su punto de mayor trascendencia en que si bien la reinvención es un hecho maravilloso, también representa socialmente una pérdida de poder frente a las construcciones que no re reinventan con la luz del día, como la propiedad, la capacidad de crear representaciones sociales, etcétera. Nos toca enfrentar, en nuestra práctica 
investigativa las tensiones existentes en un presente ensanchado que a fuerza de negar las memorias también niega la historia de nuestros colectivos. Así nuestro presente, como aquellas lagunas, que al secarse tienen por mucho tiempo forma de pantano. Enfrentar estos dilemas puede ser la diferencia entre hundirse y pisar firme. 


\section{Referencias bibliográficas.}

Angenot, M. (2010). El discurso social. Los limites históricos de lo pensable y lo decible. Buenos Aires: Siglo XXI.

Ankersmit, F. (2001). "The postmodernist privatization of de past”, en historical representation. Stanford: Stanford University Press.

Bernard, C., \& Gruzinski, S. (1996). Historia del nuevo mundo, del descubrimiento a la conquista. La experiencia europea 1492-1550. México: Fondo de Cultura Económica.

Castells, M. (2009). Comunication power. New York: Oxford.

Chomsky, N., \& Herman, E. (1988). Manufacturing consent: The political economy of mass media. New York: Pantheon Books.

Dussel, E. (1994). El encubrimiento del indio:1492. (Hacia el origen de la modernidad). México: Editorial Cambio XXI.

Halbawchs, M. (1992). On collective memory. Chicago: The University Chicago Press.

Hijos de México. (14 de Octubre de 2014). Obtenido de hijosdemexico.org: www.hijosmexico. org/index-ayotzinapa

Nora, P. (1984). Entre mémorie et histoire. La problematique des lieux", en Lex Lieux de mémorie. Paris: Gallimard.

Palti, E. (2003). La nación como problema Los historiadores y la "Cuestión nacional". Buenos Aires: Fondo de Cultura Económica.

Pappe, S. (2007). "Memoria versus historia". En M. Aguiluz Ibarguen, \& G. Waldman M, Memorias )in)cógnitas. Contiendas en la historia. México: UNAM.

Ramonet, I. (1986). La tiranía de la comunicación. Buenos Aires: Ramonet.

Richard, N. (2007). Fracturas de la memoria. Arte y pensamiento crítico. Buenos Aires: Siglo XXI.

Ricoeur, P. (1999). La lectura del tiempo pasado: memoria y olvido. París: Arrecife Producciones.

Ricoeur, P. (2003). La memoria, la historia, el olvido. Madrid: Editorial Trotta.

Tasso, P. (2014). "La historiografia oficial de 1968" Tesis de doctorado en historiografia. México: Universidad Autónoma de México.

Wrigth Mills, C. (1964). "Acciones situadas y vocabularios de motivos", en Poder, politica, pueblo. México: Fondo de Cultura Económica.

Zemelman, H. (2000). "En torno de la memoria y el futuro". Contextos: Contextos: Revista de humanidades y ciencias sociales, 131-140. 